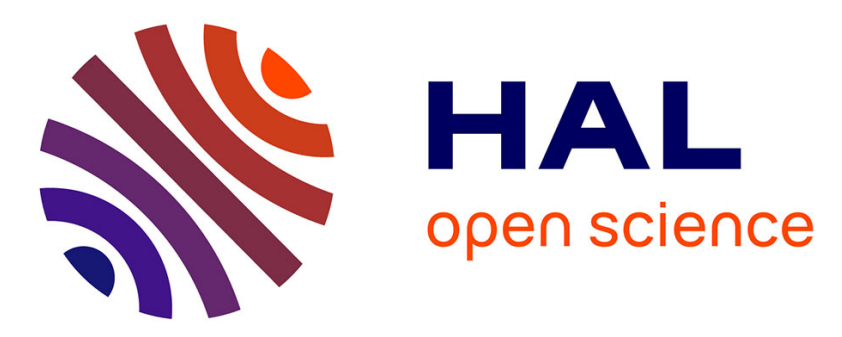

\title{
The onset of dilatant behaviour in non-inertial flow of dilute polymer solutions through channels with varying cross-sections
}

G. Chauveteau, M. Moan

\section{> To cite this version:}

G. Chauveteau, M. Moan. The onset of dilatant behaviour in non-inertial flow of dilute polymer solutions through channels with varying cross-sections. Journal de Physique Lettres, 1981, 42 (10), pp.201-204. 10.1051/jphyslet:019810042010020100 . jpa-00231909

\section{HAL Id: jpa-00231909 https://hal.science/jpa-00231909}

Submitted on 1 Jan 1981

HAL is a multi-disciplinary open access archive for the deposit and dissemination of scientific research documents, whether they are published or not. The documents may come from teaching and research institutions in France or abroad, or from public or private research centers.
L'archive ouverte pluridisciplinaire $\mathbf{H A L}$, est destinée au dépôt et à la diffusion de documents scientifiques de niveau recherche, publiés ou non, émanant des établissements d'enseignement et de recherche français ou étrangers, des laboratoires publics ou privés. 


\title{
LE JOURNAL DE PHYSIQUE-LETTRES
}

\section{The onset of dilatant behaviour in non-inertial flow of dilute polymer solutions through channels with varying cross-sections}

\author{
G. Chauveteau (*) and M. Moạn (**) \\ (*) Institut Français du Pétrole, B.P. 11, 92506 Rueil-Malmaison, France \\ (**) Laboratoire d'Hydrodynamique Moléculaire, Faculté des Sciences, 29283 Brest, France
}

(Reçu le 5 mars 1981, accepté le 26 mars 1981)

\begin{abstract}
Résumé. - La viscosité apparente de solutions diluées de polymère lors d'écoulements non inertiels dans des canaux constitués de tubes courts ou de fentes séparées par des expansions cesse de suivre un comportement pseudoplastique en loi puissance au-delà d'une vitesse de cisaillement critique calculée pour la section contractée. Le produit de cette vitesse de cisaillement critique par le temps de relaxation de Rouse est à peu près constant pour différents polymères en pelote, différentes viscosités du solvant et différentes concentrations en polymère, indépendamment de la forme géométrique exacte des canaux. Quand la vitesse de cisaillement critique est atteinte, la vitesse d'élongation maximale dans les sections convergentes de l'écoulement est supérieure à l'inverse du temps de relaxation de Rouse. On s'attend dans ces conditions à une élongation des macromolécules et on peut interpréter le comportement dilatant par l'augmentation de la dissipation visqueuse accrue par suite de l'état allongé des macromolécules dans les parties convergentes de l'écoulement.
\end{abstract}

\begin{abstract}
The apparent viscosity of dilute polymer solutions in non-inertial flows through channels consisting of successive short tubes or slits separated by expansions displays a marked divergence from shear-thinning powerlaw behaviour beyond a critical shear rate calculated for constricted sections. The product of this critical shear rate by the Rouse relaxation time was found to be nearly constant for various coil polymers, solvent viscosities and polymer concentrations, independently of the exact geometric shape of the channels. When the critical shear rate is reached, the maximum stretch rate in the converging sections is greater than the inverse of the Rouse relaxation time. An elongation of macromolecules is thus expected and the dilatant behaviour can be attributed to the increased viscous dissipation due to the elongated state of macromolecules in the converging parts of flow.
\end{abstract}

1. Introduction. - Many studies dealing with flow through porous media have shown that some dilute polymer solutions exhibit a strong dilatant behaviour, namely an increase in apparent viscosity, when the flow rate exceeds a critical value [1-4]. This dilatant behaviour, which is observed even when the flow is quite non-inertial, has often been attributed to the variations in cross-section existing in porous media. But some disagreement among authors remains about the mechanism occurring at the molecular level, which is responsible for this dilatant behaviour. The present study aims to relate the onset of this dilatant behaviour to a characteristic time of the macromolecule. In order to do this, we performed experiments in various simplified models of porous media, in which maximum shear rates in constricted sections can be evaluated as a reference for the deformation rate field.

2. Experimental. - The first type of model was two-dimensional and consisted of short slits separated by large expansions. The second was three-dimensional and very similar, i.e. a series of short capillaries separated by cylindrical expansions. These models with their dimensions are shown in figure 1 . The wall shear rate $\dot{\gamma}$ in the straight constricted sections was calculated from flow rate and dimensions. This parameter is used as a reference for the deformation rates for a quantitative discussion of the results, instead of the maximum stretch rate $\dot{\varepsilon}$ in the converging sec- 
TWO-DIMENSIONAL MODELS

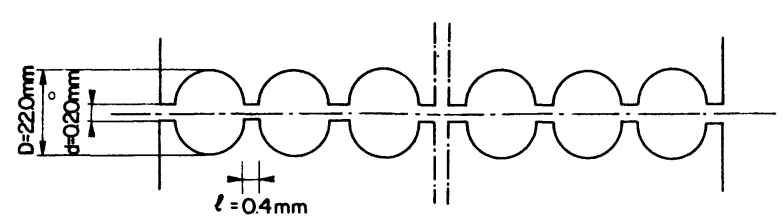

Thickness $2.5 \mathrm{~mm}, \frac{l}{\mathrm{~d}}=2,10$ Constricted Sections.

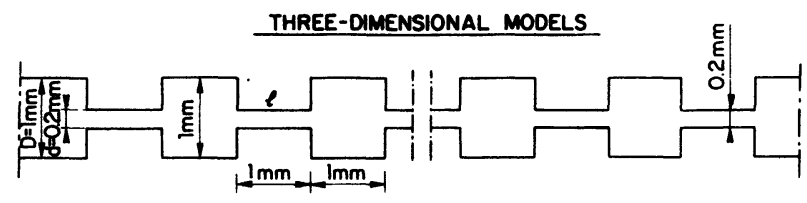

$\frac{\ell}{d}=5,45$ Constricted Sections

Fig. 1. - Diagram of two-dimensional and three-dimensional models.

tions, because $\dot{\varepsilon}$ depends on flow pattern and cannot be calculated. Nevertheless, for flow rates less than those corresponding to the onset of dilatant beha- viour, the maximum value of $\dot{\varepsilon}$ was determined as a function of $\dot{\gamma}$ by laser anemometry measurements in very similar conditions [5]. The experiments consisted in injecting polymer solutions through the tubes and measuring the pressure drop between the upstream and downstream reservoirs. The liquid flow was provided by an infusion pump used in clinical applications for injecting small volumes of liquids at constant and reproducible flow rates. The reservoirs and the tube were maintained at $25^{\circ} \mathrm{C}$ or $30^{\circ} \mathrm{C}$.

Differential pressures were measured by means of U-tube manometers or an electronic manometer. The Reynolds numbers for flow rates of interest near the onset were always less than 10 so that inertial forces can be considered as negligible.

Various hydrosoluble polymers, hydrolyzed polyacrylamide (HPAM), non-hydrolyzed polyacrylamide (PAM) and poly-ethylene-oxide (PEO) (table I) were used in this study. Their macromolecular weights are very high, and their macromolecules have a coil conformation. Variations in solvent viscosity were obtained for PAM solutions by adding glycerol to

Table I. - Fluid properties.

\begin{tabular}{|c|c|c|c|c|}
\hline Polymer & Molecular weight & Solvent & Concentration & $\begin{array}{c}\text { Overlap parameter } \\
c .[\eta]_{0}\end{array}$ \\
\hline HPAM & $7 \times 10^{6}$ & water $(20 \mathrm{~g} / 1 \mathrm{NaCl})$ & $21<c<1357$ & 0.07 to 4.7 \\
\hline \multirow{3}{*}{ PAM } & \multirow{3}{*}{$4.5 \times 10^{6}$} & water $(5 \mathrm{~g} / \mathrm{l} \mathrm{NaCl})$ & $206<c<1650$ & 0.23 to 1.88 \\
\hline & & $\begin{array}{l}75 \% \text { water }+ \\
25 \% \text { glycerol } \\
(5 \mathrm{~g} / \mathrm{l} \mathrm{NaCl})\end{array}$ & 1650 & $\simeq 2$ \\
\hline & & $\begin{array}{l}50 \% \text { water }+ \\
50 \% \text { glycerol } \\
(5 \mathrm{~g} / \mathrm{NaCl})\end{array}$ & 1650 & $\simeq 2$ \\
\hline PEO & $4.0 \times 10^{6}$ & distilled water & 2000 & $\simeq 2.2$ \\
\hline
\end{tabular}

water. Polymer concentrations were changed to a large extent from dilute (isolated macromolecules) to intermediate regime (overlapped macromolecules, but not strongly entangled) as shown by the values of the Simha overlap parameter $c[\eta]_{0}$ given in table $\mathrm{I}$; $[\eta]_{0}$ is the intrinsic viscosity at zero shear rate and $c$ is the polymer concentration.

3. Results and discussion. - Typical plots of the " apparent relative viscosity" $\eta_{\mathrm{a}, \mathrm{r}}$ as a function of the wall shear rates $\dot{\gamma}$ calculated for constricted sections are shown in figures 2 and 3 for models 1 and 2. -The apparent relative viscosity, which is the ratio between the total pressure drop during polymer flow and total pressure drop during solvent flow, is equal to the relative shear viscosity $\eta_{\mathrm{r}}$ for shear rates lower

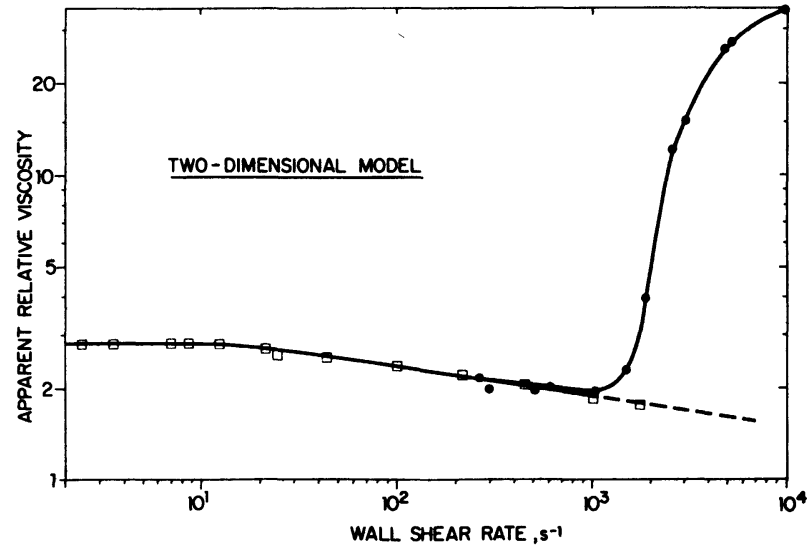

Fig. 2. - Dilatant behaviour observed in the two-dimensional model for the HPAM polymer $(c=340 \mathrm{ppm})$. 


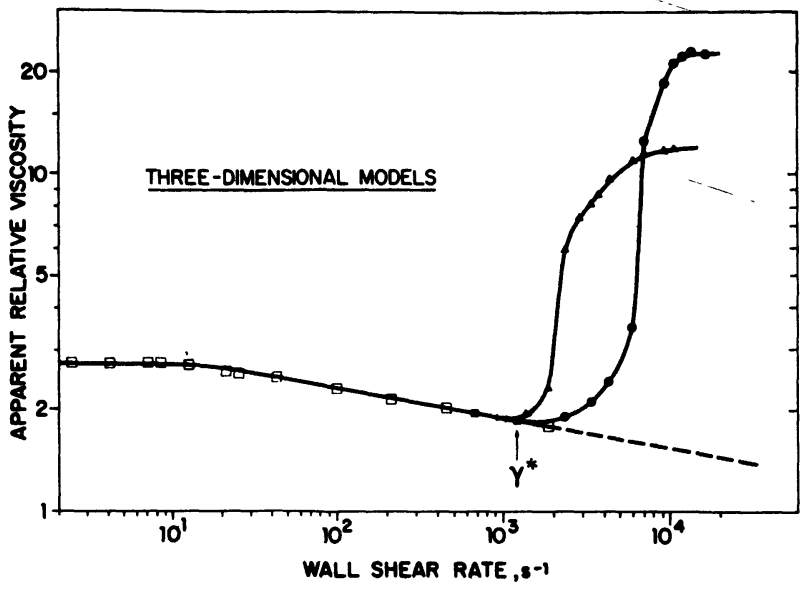

Fig. 3. - Dilatant behaviour observed in the three-dimensional model for the HPAM polymer $(c=340 \mathrm{ppm}): \Delta$ model with 45 constricted sections; model with one constricted section.

than a critical shear rate $\dot{\gamma}^{*}$. Beyond this critical shear rate, we observe a divergence from the power-law behaviour similar to the one previously observed for capillaries of the same radius having different lengths [6]. Due to the relatively low value of the length-to-diameter ratio $l / r=10$, this divergence gives an increase in apparent viscosity, a phenomenon often designated by the term dilatant behaviour. In figure 3 , we have also plotted the $\eta_{\mathrm{a}, \mathrm{r}}-\dot{\gamma}$ curve for a model having only one constricted section identical to that of model 2. The onset $\dot{\gamma}^{*}$ of dilatant behaviour is nearly independent of the number of constricted sections. These observations are consistent with the interpretation we gave in a previous publication for the very high entrance pressure drop observed in a capillary [6]. We assumed that macromolecules are elongated by extensional flow near the entrance to constricted sections when the stretch rate $\dot{\varepsilon}$ is high enough, i.e. $\dot{\varepsilon}$ higher than a critical value $\dot{\varepsilon}^{*}$.

Now we will examine the variation of the critical shear rate $\dot{\gamma}^{*}$ as a function of the some physicochemical parameters : solvent viscosity, nature of the polymer and polymer concentration. For this purpose a characteristic time of the macromolecule is derived from Rouse's theory [7]. The longest relaxation time of the macromolecule in a solution $\tau_{1}$ is calculated by the following equation

$$
\tau_{1}=\frac{6}{\pi^{2}} \cdot \eta_{\mathrm{s}} \cdot \frac{\eta_{\mathrm{r} 0}-1}{c} \cdot \frac{M}{R T}
$$

where $\eta_{\mathrm{s}}$ is the solvent viscosity, $\eta_{\mathrm{r} 0}$ the relative viscosity at zero shear rate and $M$ the molecular weight of the polymer. The effect of solvent viscosity and the nature of the polymer were tested in the two-dimensional models. The results are given in table II. Given the accuracy in the determination of $\dot{\gamma}^{*}$, the product $\dot{\gamma}^{*} . \tau_{1}$ can be considered to be a constant, between 5 and 9 , independent of the two parameters tested.

Table II. - Onset of dilatant behaviour : effect of solvent viscosity and nature of polymer (two-dimensional model).

\begin{tabular}{|c|c|c|c|c|}
\hline Polymer solution & Solvent & $\tau_{1} \times 10^{3} \mathrm{~s}$ & $\dot{\gamma}^{*}, \mathrm{~s}^{-1}$ & $\dot{\gamma}^{*} \times \tau_{1}$ \\
\hline \multirow{3}{*}{$c=1650 \mathrm{ppm}$} & $\begin{array}{c}\text { water } \\
(5 \mathrm{~g} / 1 \mathrm{NaCl})\end{array}$ & 2.0 & 2800 & 5.6 \\
\hline & $\begin{array}{c}\text { water }(75 \%) \\
\text { glycerol }(25 \%) \\
(5 \mathrm{~g} / 1 \mathrm{NaCl})\end{array}$ & 5.2 & 1700 & 8.8 \\
\hline & $\begin{array}{r}\text { water }(50 \%) \\
\text { glycerol }(50 \%) \\
(5 \mathrm{~g} / 1 \mathrm{NaCl})\end{array}$ & 15.8 & 560 & 8.8 \\
\hline $\begin{array}{c}\text { HPAM } \\
c=\quad 340 \mathrm{ppm}\end{array}$ & $\begin{array}{c}\text { water } \\
(20 \mathrm{~g} / 1 \mathrm{NaCl})\end{array}$ & 6.40 & 1200 & 7.7 \\
\hline $\begin{array}{c}\text { PEO } \\
c=2000 \mathrm{ppm}\end{array}$ & water & 1.45 & 4500 & 6.5 \\
\hline
\end{tabular}

Using the three-dimensional tubular model, the effect of the polymer concentration was tested in a wide concentration range from 21 to $1360 \mathrm{ppm}$. From the $\eta_{\mathrm{a}, \mathrm{r}}-\dot{\gamma}$ curves shown in figure 4 , the values of $\dot{\gamma}^{*}$ and $\tau_{1}$ were obtained and are given in table III.
This time, the product of the Rouse relaxation time by the critical shear rate decreases slightly with polymer concentration but all values are also found between 9 and 13.

Taking into account the significant variation obtain- 


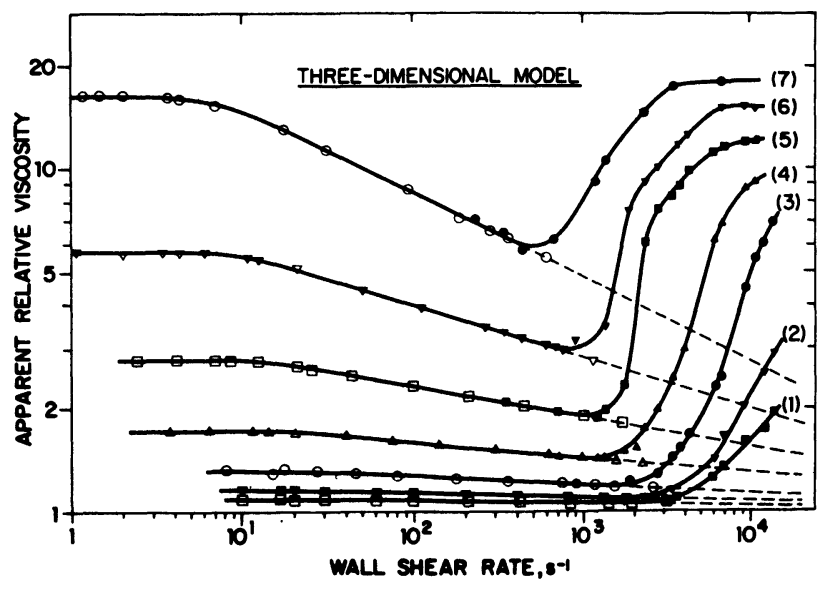

Fig. 4. - The effect of polymer concentration on the dilatant behaviour (three-dimensional model; HPAM polymer) : (1) $c=21 \mathrm{ppm}$; (2) 42 ; (3) 85 ; (4) 170 ; (5) 340 ; (6) 680 ; (7) 1360 . For these concentrations, the shear viscosity (open symbols) was determined by Siregar [8]

Table III. - Onset of dilatant behaviour : effect of the polymer concentration (three-dimensional model).

\begin{tabular}{|c|r|r|r|r|r|r|r|}
\hline$c(\mathrm{ppm})$ & 21 & 42 & 85 & 170 & 340 & 680 & 1360 \\
\hline$\tau_{1} \times 10^{3}(\mathrm{~s})$ & 4.4 & 4.6 & 4.7 & 5.4 & 6.4 & 8.7 & 14.3 \\
\hline$\dot{\gamma}^{*}\left(\mathrm{~s}^{-1}\right)$ & 3100 & 2900 & 2400 & 1850 & 1550 & 1160 & 610 \\
\hline$\dot{\gamma}^{*} \times \tau_{1}$ & 13.6 & 13.1 & 11.2 & 10 & 9.9 & 10.1 & 8.7 \\
\hline
\end{tabular}

ed for $\tau_{1}$ and the value of the ratio $\dot{\varepsilon} / \dot{\gamma}(\dot{\varepsilon} / \dot{\gamma} \approx 0.4)$ for similar solutions [5] (340 ppm dissolved in a mixture of $80 \%$ glycerol and $20 \%$ water), it can be conclud- ed that the onset of dilatant behaviour occurs when the stretch rate in the converging zone is sufficiently higher than the inverse of the Rouse relaxation time $\left(\dot{\varepsilon}_{.} \tau_{1} \approx 4\right)$ predicted by theoretical investigations [9-11]. Moreover, the slight variation in the product $\gamma^{*} \cdot \tau_{1}$ with polymer concentration is consistent with the hypothesis of a constant value of $\dot{\varepsilon}^{*} \cdot \tau_{1}$ because the ratio $\dot{\varepsilon} / \dot{\gamma}$ is expected to decrease when the polymer concentration decreases, i.e., the solution is more and more Newtonian.

4. Conclusion. - Experiments performed in channels consisting of successive contractions and expansions have shown that dilatant behaviour occurs when the maximum stretch rate in the flow is higher than the inverse of the Rouse relaxation time. Thus, the dilatant behaviour can be explained by the sudden increase in viscous dissipation in converging sections when macromolecules have been stretched by hydrodynamic forces. The obvious similarity of dilatant behaviour in porous media [12] suggests that the same mechanism occurs, as previously, predicted [11] or claimed [4, 10]. A quantitative comparison between dilatant behaviour in channels with varying crosssections and in porous media is now being made in order to obtain a definite conclusion.

Acknowledgments. - The authors wish to acknowledge the financial assistance provided by the Délégation Générale à la Recherche Scientifique et Technique (DGRST) and the Association de Recherches sur les Techniques d'Exploitation du Pétrole (ARTEP). They also wish to thank S. Ghoniem for his help in performing some experiments.

\section{References}

[1] Dauben, D. L. and Menzie, D. E., J. Pet. Technol. (1967) 1065.

[2] Marshall, R. J. and Metzner, A. B., Ind. Eng. Chem. Fundamentals 6 (1967) 393.

[3] Desremaux, L., Chauveteau, G. and Martin, M., Rev. Inst. Fr. Pet. 26 No 6 (1971) 495.

[4] JAMES, D. F. and MaC LAREN, D. R., J. Fluid. Mech. 70 (1975) 733.

[5] HoA, N. T., private communication.
[6] Moan, M., Chauveteau, G. and Ghoniem, S., J.N.N.F.M. 5 (1979) 463.

[7] Rouse, P. E., J. Chem. Phys. 21 (1953) 1272.

[8] Siregar, S., Thesis, Bordeaux (1980).

[9] De Gennes, P. G., J. Chem. Phys. 60 (1974) 5030.

[10] Marucci, G., Polym. Eng. Sci. 15 (1975) 229.

[11] Daoudi, S., J. Physique 36 (1975) 1285.

[12] Chauveteau, G., Ann. Meeting of the Soc. of Rheol., Houston (1978). 